\title{
ATENÇÃO À SAÚdE DA CRIANÇA: PERSPECTIVA DA PRÁTICA DE ENFERMAGEM COMUNITÁRIA*
}

\author{
Akemi Iwata Monteiro** \\ Maria das Graças Carvalho Ferriani***
}

MONTEIRO, A.I.; FERRIANI, M.G.C. Atenção à saúde da criança: perspectiva da prática de enfermagem comunitária.

Rev.latino-am.enfermagem, Ribeirão Preto, v. 8, n. 1, p. 99-106, janeiro 2000.

O objetivo do presente trabalho é analisar a prática de enfermagem na assistência comunitária à saúde da criança e apontar perspectivas dessa prática para o próximo milênio. O estudo foi desenvolvido através de revisão da literatura sobre o tema, abordando, de forma sintética, a situação da saúde da população brasileira, e da criança, em particular, dentro do atual contexto social. Fez-se uma breve reflexão sobre a história da prática de atenção à saúde da criança e sobre a prática atual de enfermagem comunitária, observando-se que esta é realizada à luz do Programa Oficial de Assistência à Saúde da Criança. A perspectiva dessa prática é acompanhar o crescimento e desenvolvimento da criança no seio familiar, num trabalho multiprofissional de visita domiciliar e grupos de mães, nos quais uma enfermeira, co-participante, se destaca por sua formação em saúde preventiva e promocional.

UNITERMOS: saúde infantil, enfermagem comunitária, enfermagem

\section{INTRODUÇÃO}

Este trabalho se propõe analisar e discutir a prática de enfermagem comumente desenvolvida no Brasil na assistência comunitária à saúde da criança e apontar a perspectiva desta prática para o próximo milênio.

Ainda morrem 60 em cada 1000 crianças nascidas vivas no Brasil, por doenças totalmente evitáveis através das ações de saúde promocional, na qual a enfermagem se destaca pela sua formação, conforme TINOCO \& MODENA $^{18}$.

Como as ações de saúde promocional pouco se têm expandido, diferentemente do discurso oficial, na prática o que funciona é o modelo assistencial clínico individual, ancorado no pronto atendimento, na medicalização e no equipamento complexo-hospitalar. Esse modelo até hoje não tem produzido respostas satisfatórias, o que é de se lamentar por ser o país classificado como $8^{\mathrm{a}}$ economia mundial.

Na verdade, a situação sócio-econômica do país é determinada pelo modelo de desenvolvimento denominado neoliberal, que vem impondo à população $\mathrm{a}$ recessão econômica, desemprego, falta de moradia, enfim a desigualdade social, constatando-se o maior desrespeito contra o cidadão.

Contrapondo-se à onda de crescimento econômico, segundo TINOCO \& MODENA ${ }^{18}$, o país oculta a triste realidade do crescimento de bolsões de pobreza, com mais de $2 / 3$ da população que não dispõe de renda suficiente para uma condição adequada de vida. Cerca de 32 milhões de brasileiros passam fome.

Nessa conjuntura, a política de saúde não vem respondendo ao clamor da população, apesar da implementação da Reforma Sanitária (RS) em 1989. Aprovada pela Constituição de 1988, a RS, foi, na época, a grande esperança para todo brasileiro, pois baseava-se num novo conceito sobre saúde**** e instituía o Sistema Único de Saúde (SUS), o qual deveria estar implementado nos rigores da lei, a fim de corresponder à ânsia de milhares de necessitados.

No entanto, a ineficiência do modelo de atenção à saúde em vigor é traduzida em pronto atendimento, para responder exatamente ao modo de produção capitalista, isto é, objetiva a recuperação imediata da mão de obra, sem levar em consideração o trabalhador enquanto

\footnotetext{
* Trabalho apresentado a disciplina ENC-820 - Análise Crítica da Evolução da Assistência de Enfermagem

** Aluna do Programa de Doutorado Interunidades em Enfermagem da Escola de Enfermagem de Ribeirão Preto da Universidade de São Paulo

*** Professor Titular do Departamento de Enfermagem Materno-Infantil e Saúde Pública da Escola de Enfermagem de Ribeirão Preto da Universidade de São Paulo

**** Concepção de saúde conforme VIII Conferência Nacional de Saúde
} 
homem, que necessita ter saúde para produzir e reproduzir socialmente.

A saúde da criança nesse contexto não é diferente: também vem sofrendo as conseqüências do "caos da saúde". Apesar da queda das taxas de mortalidade infantil no Sul e no Sudeste, essas ainda continuam altas em algumas regiões do Norte, Nordeste e Centro-Oeste, principalmente nos meios rurais, segundo o FIBGE $^{6}$.

A maioria das crianças menores de 5 anos vem morrendo por doenças do tipo infecciosas, intestinais, respiratórias, por desnutrição e prematuridade, nas regiões Norte e Nordeste, conforme FIBGE ${ }^{6}$. Muitas crianças sobreviventes de tais problemas, apresentam diversos graus de atraso mental, traduzido em diminuição da capacidade de aprendizagem, baixo aproveitamento escolar, tornando-se adultos excluídos do sistema.

A reversão do quadro de saúde apresentado implica tomada de decisão política, no sentido de mudar o aspecto social-econômico e educacional da população, levando em consideração todas as complexas facetas que afetam a vida da criança. Enquanto isso não ocorre, os serviços de saúde e seus profissionais podem contribuir para minorar esse quadro, criando e recriando um modelo de saúde que atenda melhor a essa população.

Diante do exposto, este trabalho realiza inicialmente a descrição contextualizada da situação atual da criança. Em seguida, faz uma breve reflexão histórica sobre a prática de atenção comunitária à saúde da criança, indicando algumas práticas exercidas pelos profissionais de enfermagem, evidenciadas na área da saúde comunitária. Trata, ainda, do momento atual da prática de enfermagem comunitária, falando da consulta de enfermagem e de trabalhos com grupo de mães. Finalmente, pretende apontar perspectiva dessa prática para o próximo milênio.

\section{BREVE REFLEXÃO HISTÓRICA SOBRE A PRÁTICA DE ATENÇÃO COMUNITÁRIA À SAÚDE DA CRIANÇA}

A gravidade da mortalidade infantil, segundo ROSEN $^{12}$, foi reconhecida politicamente em 1893, nos países ocidentais, onde foram empreendidos esforços para a elevação do nível de saúde da criança, implantando-se um programa completo de bem-estar materno-infantil (visita de um clínico à criança, exame do recém-nascido), e criando-se a Divisão de Higiene Infantil, no Departamento de Saúde, em Nova York, e leis que protegiam mães e crianças.

Entretanto, foi através da "Divisão de Crianças*****, "em Nova York, que foram desenvolvidos programas de assistência, nos quais se enfatizou o bemestar da criança, do ponto de vista social, com a atuação de pessoal qualificado nessa área, conforme ROSEN ${ }^{12}$. No âmbito dos programas, destacava-se a puericultura, surgida na França no século XIX e difundida em muitos outros países, inclusive no Brasil.

O reconhecimento da importância da atenção à saúde da criança, no Brasil, segundo ROCHA ${ }^{11}$, sofreu influência da Europa ocidental, no início de 1920, sendo nesse período, criadas as primeiras leis de proteção à infância - regulamentação de trabalho do menor, da gestante e da puérpera nas fábricas, fiscalização das creches e serviços de amas-de-leite.

A história da proteção à saúde da criança no país demonstra uma trajetória similar à dos países ocidentais, onde o interesse político e o econômico sempre estiveram presentes na consecução do "bem-estar" social da população.

ORLANDI $^{9}$, analisando a história da atenção à saúde da criança, descreve a prática da puericultura adotada oficialmente pelo governo, como sendo de controle da vida familiar pela classe dominante, utilizando-se a criança como pretexto.

A prática de puericultura perdurou durante décadas e continua a existir na atualidade, sob o cognome de "Acompanhamento do crescimento e desenvolvimento da criança" embasado em um corpo conceitual que se traduz por normas e regras higiênicas a serem cumpridas pelas mães. Tal atividade vem fazendo parte de um Programa Integrado de Assistência à Criança, do Ministério da Saúde. ROCHA ${ }^{11}$ refere, a propósito desse Programa, os médicos e enfermeiros fazem atendimento curativo com pouca ênfase na prevenção e educação em saúde.

A prática de puericultura foi bem incorporada pela prática médica e, segundo ORLANDI ${ }^{9}$, havia interesses diversos e impregnados de ideologia mercantilista, o que atendia ao crescimento da indústria do leite em pó na época, substituindo a amamentação, para que as mães trabalhadoras não fossem liberadas com essa finalidade.

\section{A PRÁTICA HOJE}

Esse tipo de prática perdurou por décadas, e hoje percebe-se um tipo seletivo de atenção médica à criança,

\footnotetext{
***** Encarregada de investigar e relatar todos os assuntos referentes ao bem-estar das crianças e da vida infantil, em todas as classes do povo americano $\left(\mathrm{ROSEN}^{12}\right)$.
} 
a qual, segundo Marcondes apud ROCHA ${ }^{11}$, sofre modificações de acordo com a instituição na qual é realizada, diferindo no tempo gasto e na qualidade segundo as categorias de clientela do consultório (particular, conveniado ou público).

No consultório particular, o tempo gasto se estende de trinta a sessenta minutos, e a consulta é considerada padrão de atendimento quando a anamnese e o exame físico são os mais completos. Além do mais, a orientação é feita a cada mãe, individualmente, pela pediatra. No ambulatório da Previdência Social, o tempo gasto fica em torno de vinte minutos e o atendimento é um pouco aquém da consulta particular com supressão de alguns pontos na anamnese, no exame físico e a orientação é realizada pela enfermeira e/ou educadora sanitária. No Centro de Saúde, a duração é menos de dez minutos e a consulta é baseada apenas na indagação das condições alimentares, e do problema atual da criança, e no exame físico sucinto, e a prescrição é feita em impressos pré-formulados. A orientação também é da responsabilidade da enfermeira e/ou educadora em saúde pública, de forma individual ou grupal.

Essas distinções evidenciam quatro questões cruciais que hoje se vivenciam. Trata-se da extrema valorização da instituição privada em detrimento da pública, despendendo aquela maior tempo gasto no atendimento, padrão de atendimento o mais completo e distinção dos profissionais que atendem. Obviamente toda essa diferença só faz sentido para atender ao interesse econômico.

Os procedimentos denominados básicos e simplificados, dirigidos para atender à maioria da população, são discutidos por NOGUEIRA ${ }^{8}$. Segundo esse autor, a política na assistência de saúde à criança no Brasil encontra-se dividida em três linhas principais de ação. A primeira é baseada "na criação de estruturas permanentes que visam à integração de ações de distintas instâncias de governo e da sociedade”, a segunda é caracterizada pelas ações de caráter emergencial, para atender problemas de saúde mais evidentes, preconizando a promoção de ações eficazes e eficientes a curto prazo, com ênfase na ação "em si mesma" e no processo de mobilização social, enquanto que a terceira é a captação de recursos para garantir o funcionamento da estrutura já existente.

Comentando sobre essas três linhas de ação, o autor aponta várias falhas na estruturação da primeira linha, na qual se insere o projeto "Minha Gente," que propunha construção de CIACs***** em todo o país. Essas falhas, vão desde a concepção de atenção à saúde da criança até a coordenação do projeto. Continuando a análise, o autor refere que, dentre as ações propostas pelas linhas, a prevalente é a emergencial, que se caracteriza por uso de tecnologia de baixo custo, comprovadamente eficaz e eficiente. Nesse tipo de ação é feita a extensiva mobilização social a favor do cuidado com a infância. Esta é liderada pelos organismos não governamentais, o Fundo das Nações Unidas para a Infância (UNICEF).

Já à terceira linha vêm sendo incorporadas medidas que fazem parte do rol da sobrevivência, consideradas pelo governo brasileiro como ações básicas de saúde dentro de um programa de assistência integral à criança. As ações básicas, conforme NOGUEIRA ${ }^{8}$, "coincidem naturalmente com os itens da sobrevivência infantil, mas existem diferenças sutis na maneira de pôlas em prática, conferindo ênfase na integração às atividades usuais da rede de serviços". p. 45 Analisando essas ações o autor afirma que

"se de um lado, nos programas oficiais, o governo brasileiro tem buscado expressar principios de ação, que incorporam as prioridades assistenciais da linha de sobrevivência como parte do conjunto das atividades realizadas pelos serviços, por outro lado, na prática, o desempenho insatisfatório desses mesmos serviços deixa aberto espaço à forma de atuação que se aproxima bastante da estratégia de mobilização campanhista de recursos extra sanitário, nos modelos recomendados pela UNICEF" p.46.

Dessa forma, percebe-se o grau de complexidade em que tais ações estão envolvidas, além da correlação de forças, sem contudo favorecer os maiores interessados.

Nesse cenário, insere-se a prática de saúde da criança realizada pela enfermagem, da qual, segundo ROCHA $^{11}$, existem poucos registros de trabalhos publicados, no país. A autora descreve a experiência de atenção à criança do município de Ribeirão Preto-SP, na qual o enfermeiro é visto como coordenador de todo o processo de trabalho. As atividades desenvolvidas por esse profissional são de administração, supervisão de grupo, permanecendo eles, por isso, afastado da chamada assistência direta ao paciente. Afirma ainda a autora que a função exercida pelo enfermeiro, não se refere, especificamente, à organização da assistência de enfermagem, com melhoramento da qualidade de atenção à saúde e sim, a tarefas gerenciais voltadas para o controle e organização dos serviços.

As práticas de atenção à saúde da criança, desenvolvidas pela enfermagem, segundo ROCHA ${ }^{11}$ são aquelas vinculadas ao Programa de Assistência à Saúde 
da Criança a saber: imunização; acompanhamento do crescimento e desenvolvimento, através de consultas médicas, pré-consultas e pós-consultas, além das orientações básicas referentes a higiene alimentar e importância do aleitamento materno. Essas ações, segundo alguns autores- DUPAS ${ }^{4}$; SANTOS $^{14}$; FALEIROS et al. ${ }^{5}$ têm tido pouca repercussão social, uma vez que o modelo clínico assistencial, juntamente com a limitação econômica e social, não propicia a solução de problemas da população usuária.

Dentre os trabalhos publicados, de atenção à saúde da criança, em termos de inovação, tem-se a dos autores SALGADO et al. ${ }^{13}$, da Revista Cubana de Enfermagem, os quais desenvolveram um trabalho dentro do programa médico de família, que objetiva a integralização na atenção à família e o zelo pela saúde de todos. Nessa nova modalidade de assistência, em que há uma estreita relação médico-enfermeira-família e comunidade organizada, os autores destacam os tipos de atividades que conseguem elevar o nível profilático a cifras superiores aos $90 \%$. SUCUPIRA et al. ${ }^{17}$ relatam as experiências de atenção à criança junto a grupo de mães, no programa de saúde infantil, destacando a importância da equipe multiprofissional e a repercussão positiva de ensino de residentes médicos, propiciada pela nova metodologia. Da mesma forma, TUPINAMBÁ et al. ${ }^{19}$, explicitam o atendimento individual referente ao exame físico e, para isso, usam uma orientação rotineira de atendimento e conscientização da importância da puericultura, discussão em grupo e o exame físico realizado pela mãe ou responsável, sob supervisão da enfermeira. Esses trabalhos são os que fogem ao modelo clínico curativo.

Em recente trabalho realizado por SILVA ${ }^{16}$, sobre atenção à saúde da população infantil, no município de Natal (93/95), as doenças do aparelho digestivo, infecções intestinais, foram as mais freqüentes. Das atividades desenvolvidas pelas enfermeiras atuantes nos programas, destacaram-se as orientações individuais, palestras e consultas individuais, sem qualquer prática inovadora.

Esses poucos trabalhos referidos anteriormente apontam a instituição pública como maior prestadora de serviços à população, como também o desenvolvimento, pelos profissionais das ações de saúde, com freqüência, à luz do paradigma médico individual, seguindo programa oficial orientado pela ideologia dominante, sem direção para interesses da maioria da população.

Entre os trabalhos de enfermagem registrados, observa-se que a maioria origina-se de instituições públicas e privadas que seguem os moldes dos programas oficiais destinados à criança. Mesmo assim, uma grande parcela da população infantil não tem acesso a esse atendimento, por isso adoece e morre sem nunca ter sido atendida por serviços de saúde. Essas são crianças que algumas vezes têm sido noticiadas como desnutridas e famintas, estampadas nas páginas dos jornais, revistas e TVs. São filhos dos excluídos do sistema de produção, sem terra, sem teto, abandonados à própria sorte.

Para reverter essa situação, sabe-se que o trabalho a ser enfrentado é um desafio para a equipe multidisciplinar e intersetorial da qual a enfermeira é um componente. É preciso que a atuação da enfermagem esteja ampliada de modo a se libertar do limite proposto pelos programas, compartilhando no trabalho coletivo de saúde, para construir um processo de trabalho mais benéfico aos usuários.

\section{PERSPECTIVA DA PRÁTICA DE ENFERMAGEM PARA O PRÓXIMO MILÊNIO}

A enfermagem, assim como outras profissões, está vinculada ao processo de transformação socialeconômica e cultural do sistema. Fazendo parte do micro e do macros sistema, os enfermeiros não devem ficar alheios a tal ocorrência, pois a crise da sociedade é geral, o que significa que esses estão intimamente interligados e são interdependentes.

Segundo CAPRA ${ }^{3}$ :

"é uma crise complexa, multidimensional cujas facetas afetam todos os aspectos de nossa vida, a saúde e o modo de vida, a qualidade do meio ambiente e das relações sociais, da economia, tecnologia e política. É uma crise de dimensões intelectuais, morais e espirituais, uma crise de escala e premência sem precedentes em toda a história da humanidade. Pela primeira vez, temos que nos defrontar com a real ameaça de extinção da raça humana e de a vida no planeta", p. 19.

Com relação à crise mundial, $\mathrm{CAPRA}^{3}$ aponta vários nós críticos: a corrida armamentista (nuclear), que contamina a água, o ar e os alimentos e deteriora o meio ambiente natural; anomalias econômicas - inflação, desemprego -; esgotamento energético são as questões que estão afetando profundamente o planeta Terra.

Qual é a participação da enfermagem neste contexto? Sendo a enfermagem uma profissão desempenhada por indivíduos que vêem a realidade conforme sua formação e experiência de vida, precisa inteirar-se de um conhecimento amplo na questão da saúde para poder repensar a sua prática. Hoje, essa visão, com base em valores culturais, morais e éticos, está no auge da discussão. É preciso que a enfermagem faça uma reflexão sobre sua prática, para compreender o panorama 
de saúde já referido no item anterior em confronto com o velho paradigma de atenção à saúde.

Falando sobre um futuro sistema de saúde, CAPRA $^{3}$ acrescenta que

"a saúde consistirá, em primeiro lugar e acima de tudo, num sistema abrangente, efetivo e bem integrado de assistência preventiva. A manutenção da saúde será, em parte, uma questão individual e, em parte, uma questão coletiva, estando as duas, a maior parte do tempo, intimamente interligadas", p. 325.

Acrescenta o autor que "os individuos só podem ser responsabilizados na medida em que têm a liberdade de cuidar de si mesmos, e essa liberdade é freqüentemente cerceada por pesados condicionamentos sociais e culturais", p. 326. Nesse sentido, o autor não descarta o modelo biomédico, que tem sua importância na medida em que o enfoque for apropriado e tiver chances de ser bem sucedido, como, por exemplo, quando houver a necessidade de prescrição de medicamentos, intervenções cirúrgicas, etc. O modelo biomédico vigente hoje no país, conforme foi referido anteriormente, tem obtido pouco impacto na saúde coletiva.

Diante da pouca resolubilidade e da ineficácia do resultado da medicina hoje, a população tende a recorrer aos vários tratamentos alternativos para a cura, como, por exemplo: espiritismo, fitoterapia, curandeirismo, entre outros.

Diante do que foi exposto, entende-se que a atenção à saúde da população tende a mudar para o novo paradigma de assistência, baseado na concepção sistêmica de saúde, em que o mundo é visto em termos de relações e de integração. CAPRA ${ }^{3}$ define os sistemas como

"totalidades integradas, cujas propriedades não podem ser reduzidas às de unidades menores. Em vez de se concentrar nos elementos ou substâncias básicas, a abordagem sistêmica enfatiza princípios básicos de organização. As propriedades sistêmicas são destruidas quando um sistema é dissecado, fisica ou teoricamente, em elementos isolados. Embora possamos discernir partes individuais em qualquer sistema, a natureza do todo é sempre diferente da mera soma de suas partes". "Um outro aspecto importante dos sistemas é sua natureza intrinsecamente dinâmica. Suas formas não são estruturas rígidas, mas manifestações flexiveis, embora estáveis, de processos subjacentes", p. 260.

A concepção sistêmica de saúde é profundamente ecológica e, assim, está em harmonia com a tradição hipocrática em que se apóia a medicina ocidental. Dentro dessa concepção, o que se evidencia são os modelos assistenciais que levem em conta o homem como um ser histórico indissociável do seu meio e da sua relação de produção.

O Programa de Saúde da Família (PSF) do Ministério da Saúde é um modelo assistencial que se aproxima da concepção sistêmica, a qual visualiza o indivíduo inserido no seio familiar e na comunidade não perdendo de vista a sua relação com o meio social historicamente determinado. Nessa condição, o indivíduo é integrado à família e à comunidade, assumindo portanto, posição efetiva como sujeito do processo.

O PSF, modelo de saúde incipiente no país, por um lado, propicia às equipes multiprofissionais de saúde, uma ação ampliada e planejada, elegendo um campo de atuação estratégico- o domicílio e a comunidade-, conforme o perfil epidemiológico desenhado; por outro, favorece e incentiva a maior participação da comunidade nos assuntos da saúde. Nesse sentido, pode haver maior integração entre o serviço e a comunidade e, conforme o trabalho educativo investido, o PSF leva tanto o serviço de saúde como a comunidade a romperem com as atitudes passivas e viciadas do "cuidar," as quais são próprias do modelo biológico de saúde vigente ${ }^{3}$.

Entendendo o significado da interação do indivíduo com o meio ambiente, deixa patente a importância da educação acerca da natureza e da relação entre a doença e o tipo de vida do indivíduo. Nesse sentido, SILVA ${ }^{15}$ refere que

"a compreensão da educação e da saúde como práticas sociais de organização da vida cotidiana implica na compreensão da sociedade além de sua produção, incorporando elementos da subjetividade humana, resultante das experiências sociais mediatizadas em cada corpo (objeto aparente de intervenção das práticas de saúde) e em cada consciência (objeto aparente de intervenção da educação), em relação com os outros e com o mundo...", p. 39.

A autora, ao levantar questões da organização da vida cotidiana- corpo, consciência, interação com os outros e o mundo -, dirige a tendência do seu entendimento para a visão holística. Desse modo, percebe-se que a visão fragmentada do mundo e da cultura atual, a abordagem reducionista da ciência e o exercício da medicina orientado para o uso maciço de tecnologia levam a criar desejos e necessidades. Como resultado, o povo torna-se dependente de uma atenção à saúde curativa, ou seja cada vez mais consumista desse tipo de serviços.

É ainda nesse contexto que a enfermagem continua a atuar, no modelo clínico individual, sem 
priorizar o trabalho de saúde coletiva- visitas domiciliares, trabalhos educativos, atividades externas com grupos populacionais, vigilância sanitária e epidemiológica (ALMEIDA et al. ${ }^{1}$ ).

Todas as atividades acima citadas poderão ser desenvolvidas dentro de uma visão sistêmica e holística, como fazem as enfermeiras da equipe de saúde de uma comunidade de Cuba, que trabalham na atenção integral à família - pessoas sadias ou doentes, crianças ou adultos, mulheres grávidas ou com transtornos ginecológicos. $\mathrm{O}$ grupo vê a família como um todo único, dentro de seu ambiente, exercendo nela valiosas atividades de prevenção e promoção de saúde.

Conceitua-se a promoção da saúde, conforme Carta de Otawa (Conferência Internacional sobre Promoção de Saúde) ${ }^{2}$,

"como processo de capacitação da comunidade para atuar na melhoria da sua qualidade de vida e saúde, incluindo uma maior participação no controle deste processo”. Para complementar este conceito, a Carta acrescenta que "para atingir um estado de completo bem-estar físico, mental e social, os individuos e grupos devem saber identificar aspirações, satisfazer necessidades e modificar favoravelmente o meio ambiente" BRASIL $^{2}$, p. 6.

Com o intuito de desenvolver a saúde da população mundial, foram realizados sucessivos encontros, que resultaram, por exemplo, nas Declarações de Adelaide (Austrália, 1988) e nas Conferências em Sundsvall (Suécia, 1991) e Santa Fé (Bogotá, 1992).

Em todas as declarações sobre a promoção da saúde, ressalta-se a importância e a necessidade da reorientação dos serviços de saúde:

"o papel do setor saúde deve mover-se, gradativamente, no sentido da promoção da saúde, além das suas responsabilidades de prover serviços clínicos e de urgência. Os serviços de saúde precisam adotar uma postura abrangente, que perceba e respeite as peculiaridades culturais. Esta postura deve apoiar as necessidades individuais $e$ comunitárias para uma vida mais saudável, abrindo canais entre o setor saúde e os setores sociais, políticos, econômicos e ambientais, BRASIL ${ }^{2}$, p. 9.

No nosso país, o Sistema Único de Saúde (SUS) incorpora os pontos expressos nas quatro Declarações.

No Brasil, no momento atual, os serviços públicos ampliam o seu campo de atuação e passam a dar atenção à saúde da família. Sabe-se que a atenção à saúde familiar não é nada inovadora, uma vez que essa prática era tradicionalmente exercida pelas mulheres e posteriormente pelos médicos, desde séculos passados. No entanto, tinha perdido sua importância ao longo da industrialização e do avanço hospitalar, em meados deste século e hoje vem ressurgindo como algo inovador, entre os novos paradigmas de assistência.

HAYES $^{7}$ diz que essa é a área da saúde que mais necessita de estudos, pois ainda hoje não existem fontes que orientem os profissionais a cuidar de famílias, sendo poucos os pesquisadores que se tenham preocupado com preocupações com a relação enfermeira $\mathrm{x}$ família ou enfermeira $\mathrm{x}$ ambiente.

Para que a atenção à saúde seja estendida a todas as crianças, a enfermeira deve trabalhar no sentido de concretizar os princípios da universalização e da eqüidade. Dessa forma a atenção à saúde da criança deve ser redimensionada, de modo que a criança seja vista no seio familiar e na comunidade, necessitando-se, para esse fim, de um respaldo político e estrutural que viabilize tais ações. Como exemplo, relata-se a seguir uma experiência vivida pelas equipes de PSF de Natal-RN.

No PSF da Unidade Básica de Felipe Camarão, do município de Natal, o acompanhamento do crescimento e desenvolvimento da criança, realizada pela equipe multiprofissional se aproxima da proposta de atenção integral. A consulta de enfermagem, feita pela enfermeira, ocorre de forma articulada com a equipe multiprofissional, da qual ela é co-participante. Essa consulta é redirecionada e ampliada, estendendo-se o acompanhamento a gestantes, por meio de consulta prénatal, com diversas atividades educativas, promocionais e visitas domiciliares, para que no pós-parto a mãe retorne à unidade com a criança que será acompanhada pela equipe, a qual enfatiza a atividade educativa realizada pela enfermeira, na consulta de enfermagem. Neste processo ocorre busca ativa das crianças que nasceram e não procuraram o serviço bem como as que são faltosas do Programa de Crescimento e Desenvolvimento(CD) e atrasadas na vacinação, através de visita domiciliar.

Nas eventuais mortes da criança a equipe aciona o evento sentinela****** a fim de descobrir os prováveis fatores causais da morte.

Durante a consulta da criança, a mãe também é atendida, para discutir e eleger, se assim desejar, o método anti-conceptivo que adotará, através de Programa de Planejamento Familiar. Além disso, fazem-se exames pósparto e fornecem-se outras orientações à mãe.

Como trabalhos educativos desenvolvidos

****** O evento sentinela, segundo Rutstein et al. (1976) apud PENNÁ ${ }^{10}$, é a ocorrência de doença, invalidez ou morte desnecessária. Daí define-se como sendo a coleta de informação a partir do fato negativo, do que foi previamente definido como o que não deve ocorrer 
naquela Unidade Básica, tem-se reunião mensal com grupos de mães que desejam inscrever suas crianças no Programa de CD e no pré-natal, realizados por enfermeira e psicóloga e reunião com assistente social. Uma reunião semanal um com grupo de mulheres, sobre planejamento familiar, é realizada por uma enfermeira.

É no trabalho multiprofissional que ocorre a atenção integral à criança. Esta atenção é planejada conforme perfil epidemiológico atualizado nas reuniões semanais, possibilitando conhecer melhor o objeto do trabalho e o meio, a fim de obter-se a maior satisfação da clientela, com a maior aproximação à realidade trabalhada.

A experiência descrita não é isenta de problemas, pois é praticada numa conjuntura social onde o modelo biológico de saúde é hegemônico e, valorizado pela política de economia neoliberal. As equipes têm vivenciado diversos tipos de dificuldades na viabilização dessa experiência, que exige maior compromisso e consistência para enfrentar o poder do modelo de saúde vigente.

Assim, entende-se que a atenção à saúde da criança hoje realizada no âmbito dos centros de saúde, poderia ser repensada no sentido de mudar o eixo de atenção à saúde para a perspectiva preventiva e promocional, levando em consideração a criança no seio familiar e ecológico, sem, entretanto, descartar a atenção individual e curativa.

Para desenvolver o novo paradigma de enfermagem, acredita-se na exigência de um estudo crítico da área, que requer o esforço de todos- o órgão formador, os pesquisadores e assistenciais- trabalhando juntos com o objetivo de contribuir para a melhoria da saúde da população. Faz-se necessário repensar os valores éticos, morais e culturais que orientam a visão de mundo do indivíduo, compreender a visão holística de atenção à saúde, desmistificar a representação de gênero nas relações sociais da mulher, definir melhor o objeto de trabalho, o instrumento e a qualidade do produto, enfim a enfermagem deve também contribuir para o bem-estar do indivíduo, da família, da sociedade e do ambiente ecológico.

\section{CONSIDERAÇÕES FINAIS}

O Programa "Assistência Integral à Saúde da Criança”, em vigor, é regido por ações de caráter emergencial com vistas a problemas de saúde mais evidentes, preconizando, para esse fim, ações eficazes e eficientes a curto prazo. Entretanto, no panorama pósimplementação deste programa, percebe-se que a maioria das ações ocorrem num modelo tradicional de atendimento em detrimento de um trabalho educativo e preventivo, o que o caracteriza como pouco resolutivo.

Os trabalhos educativos e preventivos são ações realmente complexas, porém eficazes, uma vez que, concordando com SILVA ${ }^{16}$ as ações são dirigidas "em cada consciência (objeto aparente de intervenção da educação) em relação com os outros e com o mundo...", p. 39.

Apesar de saber-se que a política neoliberal do governo não favorece a saúde, na área preventiva e educacional, é preciso que a enfermagem repense a sua prática cotidiana, para redirecionar suas ações, no sentido holístico, em que a criança é vista no seio familiar e comunitário.

O que está sendo praticado como mais promissor na área de saúde comunitária são as atividades desenvolvidas no PSF. As visitas domiciliares à família da criança, os trabalhos ou reuniões em grupo, a saúde promocional nas creches e a consulta de enfermagem, no acompanhamento do crescimento e desenvolvimento da criança, são as ações mais discutidas e eleitas como viáveis no país. Todas elas são realizadas pela equipe multiprofissional, de forma articulada e sistematizada, com base no perfil epidemiológico atualizado. A enfermeira, sendo uma profissional capacitada no trabalho promocional, representa um elo entre os profissionais e a comunidade.

Acredita-se que para adotar essa nova forma de atuação a enfermagem deve mudar o seu olhar de mundo, refletindo sobre seus valores éticos, morais, culturais e ecológicos, estes últimos, pouco valorizados nos currículos acadêmicos, apesar de hoje estarem sendo assunto do momento, pois significam a segurança da perpetuação da vida neste planeta Terra.

\section{HEALTH NURSING IN THE CARE OF CHILDREN: PERSPECTIVES OF THE COMMUNITY NURSING PRACTICE}

The study aims at analysing the community health nursing practice in the care of children and to point out the perspectives for the coming millenium. The study was conducted by review of the literature. It provides a brief synthesis of the current social context and a short historic reflection about health practices with children and community health nursing practice. It is observed that the practice of nursing is conducted according to the official Health Assistance Program for Children. Despite its goals, however, the program has not been efficient. In this way it will be valued the multiprofessional work in the accompaniment of the growth and developement, domiciliary visit, and "groups of mothers" in which the nurse will be a coparticipant of the staff, with the great contribuition that health professionals with preventions and promotions background frequently offer. 


\section{LA ATENCIÓN A LA SALUD DEL NIÑO: PERSPECTIVES EN LA PRÁCTICA DE LA ENFERMERÍA EN LA COMUNIDAD}

El objetivo del presente trabajo es analisar la práctica de enfermería en la asistencia del niño en la comunidad y colocar algunas perspectivas de esta practica para el milenio. El estudio fué desarrollado a través de una revisión de la literatura sobre el tema. Abordando de forma sintetica, la situación de la salúd de la población brasileña y del niño en particular, en el actual contexto social. E hace una reflexión sobre la historia de la práctica en la atención a la salud del niño y sobre la práctica actual de la enfermería comunitaria, observandose que ésta es realizada a la luz del Programa Oficial de la Asistencia a la Salud del Niño. La perspectiva de ésta práctica es acompañar el crecimiento y desarrollo del niño en el seno familiar, en un trabajo multidisciplinario de visita domiciliaria y grupos de madres, en los cuales una enfermera, co-participante, se destaca por su formación en salud preventiva y promocional.

TÉRMINOS CLAVES: salud del niño, enfermería en salud comunitaria, enfermería

\section{REFERÊNCIAS BIBLIOGRÁFICAS}

01. ALMEIDA, M.C.P.de; MELLO, D.F.de; NEVES, Z.A.de S. O trabalho de enfermagem e sua articulação com o processo de trabalho em saúde coletiva: rede básica de saúde em Ribeirão Preto. Rev. Bras. Enfermagem, Brasília, v. 44, n. 2/3, p. 64-75, abr/set. 1991.

02. BRASIL. Ministério da Saúde. Promoção da saúde: Carta de Otawa, Declaração de Adelaide, Sundsvall e Santa fé de Bogotá. Tradução Luiz Fernando Fonseca. Brasília,1996.

03. CAPRA, F. O ponto de mutação. São Paulo: Cultrix, 1982.

04. DUPAS, G. Considerações sobre o estado de saúde da criança. Rev. Esc. Enfermagem USP, São Paulo, v. 27, n. 3, p. 362-71, dez. 1993.

05. FAlEIROS, J.J.; PINTO, A.C.; FARIA, L.H. Promoção de saúde - Avaliação da puericultura em população de baixa renda. Rev. AMRIGS, Porto Alegre, v. 33, n. 4, p. 277-80, out./dez. 1989.

06. FUNDAÇÃO INSTITUTO BRASILEIRO DE GEOGRAFIA E ESTATÍSTICA. Crianças e adolescentes: indicadores sociais. Rio de Janeiro, 1992. v. 4, p. 1-15.

07. HAYES, V.E. Searching for family nursing practice knowledge. In: THORNE, S.E.; HAYES, V.E. Nursing praxis. Columbia: Sage, 1996. Cap. 4, p. 54-63.

08. NOGUEIRA, R.P. Políticas de assistência de saúde à criança e estrutura de serviços. CADERNO CBIA, Rio de Janeiro,v.5, p.42-52, jan./mar. 1993.

09. ORLANDI, O.V. Teoria e prática do amor à criança: introdução à pediatria social no Brasil. Rio de Janeiro: Jorge Zahar, 1985.
10. PENNÁ, M.L.F. Condição marcadora e evento sentinela na avaliação de serviço de saúde. In: Desenvolvimento gerencial de unidade básica de saúde do distrito sanitário: projeto GERUS. Brasília, MS/FNS/OPS, 1995. p. 185-92.

11. ROCHA, S.M. Puericultura e enfermagem. São Paulo: Cortez, 1987.

12. ROSEN, G. Uma história da saúde pública. São Paulo: UNESP/HUCITEC/ ABRASCO, 1994.

13. SALGADO, M. et al. La enfermera en la atencion del niño en el plan del medico de la família. Area urbana y zonas montañosas. Rev. Cuba. Enferm., v. 4, n. 1/2, p. 153-62, enero-agosto 1988.

14. SANTOS, M.P.dos. Avaliação da qualidade dos serviços públicos de atenção à saúde da criança sob a ótica do usuário. Rev. Bras. Enfermagem, Brasília, v. 48, n. 2, p. 109-19, abr./jun. 1995.

15. SILVA, J.O. Educação em saúde: notas para a discussão de um campo temático. Saúde em Debate, n. 42, p. 36-9, março 1994.

16. SILVA, C.O. A enfermagem na atenção à saúde da população de crianças e adolescentes no município de Natal. 1996. /Trabalho realizado como bolsista PIBIC - CNPq Natal-RN/.

17. SUCUPIRA, A.C.S.L. et al. Grupo de mães: uma experiência de ensino da puericultura. Pediatria, São Paulo, v. 9, p. 53-8,1987.

18. TINOCO, A.L.A.; MODENA, C.M. As políticas populacionais e de saúde e seus reflexos na família. Informe Epidemiol.SUS, v. 5, n. 1, p. 49-58, jan./mar.1996.

19. TUPINAMBÁ, L.C.T.de A. et al. O atendimento de enfermagem em grupo no programa de saúde da criança. Acta Paul. Enfermagem. São Paulo, v. 1/2, p. 38-41, abr./jun.1988.

Recebido em: 18.5 .98

Aprovado em: 7.7.99 